\title{
Complex post-larval dispersal processes in Atlantic cod revealed by age-based genetics and relatedness analysis
}

\author{
John B. Horne ${ }^{1, *}$, Ian R. Bradbury ${ }^{2}$, Ian G. Paterson ${ }^{1}$, David Hardie ${ }^{3}$, \\ Jeffrey Hutchings ${ }^{1,4}$, Benjamin J. Laurel ${ }^{5}$, Paul V. R. Snelgrove ${ }^{6}$, Corey J. Morris ${ }^{2}$, \\ Robert S. Gregory ${ }^{2}$, Paul Bentzen ${ }^{1}$
}

\footnotetext{
${ }^{1}$ Marine Gene Probe Laboratory, Department of Biology, Dalhousie University, 1355 Oxford Street, Halifax, NS B3H 4R2, Canada

${ }^{2}$ Department of Fisheries and Oceans Canada, 80 E. White Hills Road, St. John's, NL A1C 5X1, Canada

${ }^{3}$ Department of Fisheries and Oceans Canada, Dartmouth, NS B2Y 4T3, Canada

${ }^{4}$ Centre for Ecological and Evolutionary Synthesis, Department of Biosciences, University of Oslo, Oslo 0316, Norway

${ }^{5}$ Fisheries Behavioral Ecology Program, Alaska Fisheries Science Center, National Marine Fisheries Service, NOAA, Hatfield Marine Science Center, Newport, OR 97365, USA
}

${ }^{6}$ Department of Ocean Sciences and Biology Department, Memorial University of Newfoundland, St. John's, NL A1C 5S7, Canada

\begin{abstract}
Population connectivity among adult marine organisms is often attributed to dispersal during the egg/larval stage. However, post-larval dispersal may also influence connectivity, particularly when juvenile nursery habitats are separated from adult spawning habitats. Here we used age-based population genetics and kinship analysis to explore changes in population connectivity across life-history stages in Atlantic cod Gadus morhua. We genotyped 364 adult cod from the northwest Atlantic and 671 age-0 juveniles from 18 sites around eastern Newfoundland, with 72 and 15 microsatellite loci, respectively. Adult cod genotypes exhibited more population structure than was detected in juveniles across similar spatial scales. Both age classes had similar allelic diversities, but juveniles exhibited less genetic linkage and fewer departures from HardyWeinberg expectations than adults at the same loci. We detected significant kinship relationships in adult cod only within sampling locations, but 1 putative pair of juvenile kin was separated by $>500 \mathrm{~km}$. Collections of adults also displayed higher group relatedness compared to juveniles. Genetic differences between age classes are likely due to a combination of non-random mortality and non-random sorting of admixed juveniles into different adult habitats. Many studies overlook post-larval dispersal as a factor of marine population connectivity, but pre-adult relocation may be demographically and adaptively significant, in cod and other species.
\end{abstract}

KEY WORDS: Gadidae $\cdot$ Kinship $\cdot$ Newfoundland $\cdot$ Marine dispersal $\cdot$ Fisheries $\cdot$ Northwest Atlantic

\section{INTRODUCTION}

Most benthic marine organisms have the greatest dispersal potential as larvae, when they are pelagic plankton and nekton. Marine propagules are diffused by the advection of ocean circulations (Cowen \& Sponaugle 2009) and have the potential to connect populations on large spatial scales. But dispersal

${ }^{*}$ Corresponding author: john.horne@gmail.com alone does not result in population connectivity, unless migrants reach maturity and successfully reproduce in their new population (Hastings \& Botsford 2006, Pineda et al. 2007). The study of dispersal and population connectivity is of great interest to biologists, because of its relevance to conservation and predictive ecology (Kokko \& López-Sepulcre 2006). Yet, many genetic studies interested in marine popu-

(C) The authors and Fisheries and Oceans Canada 2016. Open Access under Creative Commons by Attribution Licence. Use, distribution and reproduction are unrestricted. Authors and original publication must be credited.

Publisher: Inter-Research · www.int-res.com 
lation connectivity only examine patterns in reproductive adults, which arise from both larval and postlarval processes. For species that experience ontogenetic shifts in habitat preference (e.g. depth) as post-larvae, studies targeting adults are unable to disentangle dispersal patterns across life-history phases. In such cases, it is necessary to sample recent post-larval juveniles, as well as adults.

Atlantic cod, Gadus morhua (hereafter cod), is an extensively exploited and commercially valuable species (COSEWIC 2010). It is also one of the most intensely studied marine animals in the wild, with over a century of accumulated research (COSEWIC 2010). Decades of mark-recapture studies show that although adult cod belong to discrete stocks, individuals may have highly variable seasonal patterns of movement and separate stocks may overlap geographically at certain times of year (Templeman 1974, Campana et al. 1999, Robichaud \& Rose 2004, Svedäng et al. 2007, Brattey et al. 2008). Both tagging and population genetic studies have identified discrete inshore or offshore populations (Ruzzante et al. 1999, Robichaud \& Rose 2004, Hemmer-Hansen et al. 2013, Therkildsen et al. 2013), but genetic analyses also reveal genetic differentiation among offshore spawning groups (Bentzen et al. 1996, Hutchinson et al. 2001), and among inshore stocks along coastlines at fine (tens to hundreds of kilometers) spatial scales (Knutsen et al. 2004, Jorde et al. 2007, Knutsen et al. 2011). The genetic results suggest persistent low gene flow between cod stocks over time, because such patterns often require many generations to form (Slatkin 1987, Pannell \& Charlesworth 2000; see also Ruzzante et al. 2001, Poulsen et al. 2006). Yet, the degree of genetic structuring seen in cod is somewhat surprising given the potential of pelagic eggs and larvae to disperse more widely than the genetic data suggest (Bentzen et al. 1996, Bradbury et al. 2010).

Genetic heterogeneity of cod stocks may persist through small-scale oceanographic features (i.e. eddies, fronts, gyres) that retain cod larvae close to their natal waters, particularly for inshore populations (Bradbury et al. 2000, Nielsen et al. 2005, Myksvoll et al. 2011). However, ocean currents can also transport offshore cod larvae into nearshore waters (Pepin \& Helbig 1997). In the northeast Atlantic, offshore spawning cod produce as much as $10 \%$ of the larvae settling in nearshore habitats (Knutsen et al. 2004, Stenseth et al. 2006). Nevertheless, post-settlement processes that maintain population structure in the face of extensive mixing during juvenile stages remain largely unexamined. Whether nearshore juvenile cod originating from offshore transition into inshore cod, or eventually return to join offshore spawning populations, remains unknown (but see André et al. 2016, Bonanomi et al. 2016). The disconnect between pre-adult and adult life-history stages represents one of the most significant gaps in our knowledge of cod population connectivity (Robichaud \& Rose 2004).

In spite of the scientific attention that has been given to cod, relatively few published cod studies have utilized genetic relatedness analyses. Genetic patterns of relatedness break down after only a few generations and are better suited for investigating recent connectivity than conventional population genetic analyses that average connectivity over numerous generations. As such, researchers now commonly use genetic relatedness to inform conservation and management agendas in a variety of marine species (Palsbøll et al. 2007, Hauser et al. 2011, Burgess et al. 2014, O'Reilly \& Kozfkay 2014). Here we apply agedependent genetic relatedness analyses to adult cod from Canadian waters and collections of age- 0 cod juveniles from coastal nurseries around Newfoundland. To this end, we used 2 unpublished data sets of 72 and 15 microsatellite loci, for adults and juveniles respectively, to examine the extent of pairwise and group relatedness at various spatial scales.

\section{MATERIALS AND METHODS}

\section{Sample collections}

Adult cod were collected from 6 locations in the northwest Atlantic (Fig. 1) as part of Fisheries and Oceans Canada research surveys (2004 to 2007). Fish from this study intersect with those previously used in Bradbury et al. (2010). We collected cod juveniles, consistent with age-0 size ranges, using beach seines at 18 sites around southeastern Newfoundland (Fig. 1) in October 2007. A $25 \mathrm{~m}$ long $\times 2 \mathrm{~m}$ high beach seine net (cod end mesh $9 \mathrm{~mm}$ ) was deployed from shore using a small boat to a distance of $55 \mathrm{~m}$, at a typical depth of $5 \mathrm{~m}$, sampling an area of $\sim 880 \mathrm{~m}^{2}$. Juvenile cod exhibit low rates of escape $(<5 \%$, Gotceitas et al. 1997). We collected small fin clips $(1 \times 1 \mathrm{~cm})$ from all individuals and stored them in $95 \%$ ethanol.

\section{Laboratory methods}

DNA was extracted following the protocol of Elphinstone et al. (2003), modified to work with a 96well filter plate and automated on a robotic liquid 


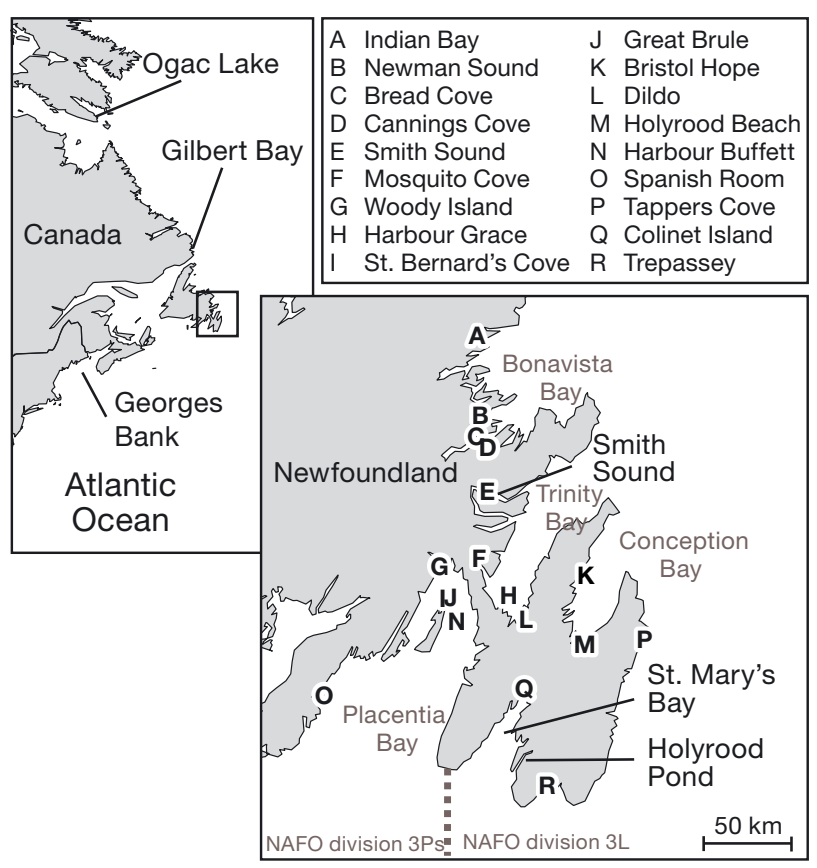

Fig. 1. Sampling locations for Atlantic cod Gadus morhua. Sample sites for adult cod are spelled out, while sample sites for juveniles are marked alphabetically from A to R. NAFO: Northwest Atlantic Fisheries Organization

handling system (Perkin Elmer). In total, we amplified 72 microsatellite loci for adult samples, 63 of which were physically linked to expressed sequence tags (EST; see Table S1 in the Supplement at www. int-res.com/articles/suppl/m556p237_supp.xls for primary sources of all loci). PCR amplification of microsatellite loci occurred in $5 \mu \mathrm{l}$ volumes containing $1 \mu \mathrm{l}$ of template genomic DNA, $0.5 \mu \mathrm{l}$ of $10 \times$ Thermopol PCR buffer (New England Biolabs), $0.5 \mu \mathrm{l}$ of $2 \mathrm{mM}$ deoxynucleoside triphosphates, $0.5 \mathrm{U}$ Taq DNA polymerase and $0.1 \mu \mathrm{M}$ of each primer. Forward primers were end-labelled with HEX or ROX dye. Thermocycler temperature profiles consisted of an initial denaturation step at $95^{\circ} \mathrm{C}$ for 2 min, followed by 25 to 30 cycles of denaturation at $95^{\circ} \mathrm{C}$ for $30 \mathrm{~s}$, $30 \mathrm{~s}$ at primer annealing temperature and $1 \mathrm{~min}$ of extension at $72^{\circ} \mathrm{C}$, and a final extension step of $72^{\circ} \mathrm{C}$ for $2 \mathrm{~min}$. Microsatellite amplicons were size fractioned using polyacrylamide gel electrophoresis and read using a LI-COR gel imaging system.

Only 15 out of 72 loci were amplified in juvenile cod (Table S1). These 15 loci represent the subset of the adult array with the highest rank $F_{\mathrm{ST}}$ scores. Independent analyses at these 15 loci in the adult samples suggest that they were among the most informative loci in the study and captured most of the same signal observed in the full array of 72 loci (see 'Results').

\section{Allele calling and population genetics}

Data were checked for the presence of null alleles and scoring errors using MicroDrop 1.01 (Wang et al. 2012). A small number of highly divergent genotypes $(<5 \%)$ are likely to have been misidentified Gadus ogac juveniles and were excluded from the analysis. Allele calls were initially organized and explored using GENALEX 6.5 (Peakall \& Smouse 2006). Datasets for adults and juveniles were produced independently and allele scores were not standardized; adult and juvenile datasets were, therefore, run independently for all analyses. To facilitate a comparison among results, the adult dataset was run twice for each analysis: once with all 72 loci, and again with a subset of the same 15 loci present in the juvenile dataset.

We calculated linkage disequilibrium (LD), heterozygote deficit and departure from Hardy-Weinberg expectations (HWE) for all loci and across populations using Markov chain Monte Carlo simulations, in GENEPOP 4.2 (Rousset 2008) with a dememorization step of 10000,100 batches and 5000 iterations per batch. p-values from multiple hypothesis testing were adjusted to an alpha value of 0.05 using the false discovery rate of Benjamini et al. (2006), computed using Bioconductor (Huber et al. 2015), in the package multtest 2.24.0 (Pollard et al. 2005). We calculated basic genetic diversity statistics and pairwise tests of population differentiation $F_{\mathrm{ST}}$ and Jost's $D$ estimator $\left(D_{\mathrm{EST}}\right)$, in $\mathrm{R}$ ( $\mathrm{R}$ Development Core Team 2014), in the diveRsity package 1.9.73 (Keenan et al. 2013), using 1000 bootstrap replicates.

Matrices of pairwise population differentiation $\left(F_{\mathrm{ST}} /\left[1-F_{\mathrm{ST}}\right]\right.$ and $D_{\mathrm{EST}} /$ [1 $\left.\left.-D_{\mathrm{EST}}\right]\right)$ of juvenile cod were investigated for a pattern of isolation-bydistance, using Mantel tests and Mantel test correlograms against raw geographic distances. In this case, geographic distance approximates the shortest overwater distance between 2 points. We also investigated relationships between genetic differentiation and pairwise Euclidean distance of 2 environmental variables: sea surface temperature and salinity (measurements taken at the same time as sampling), and with mean length of juveniles from each site. We excluded Newman Sound and Tappers Cove sites from analyses because these sites lacked sea surface temperature, salinity, and length data. The Bristol Hope site was excluded from all spatial analyses due to small sample size $(\mathrm{n}=5)$. All analyses were performed in $\mathrm{R}$, using the package ecodist 1.2.9 (Goslee \& Urban 2007).

We performed discriminant analysis of principal components (DAPC - cluster analysis and assign- 
ment testing) in the R package adegenet 1.4-2 (Jombart \& Ahmed 2011). For these analyses, missing data were replaced with the mean frequency of the corresponding allele, as per Jombart et al. (2010). The optimal number of principal components retained as predictors for discriminant analysis was determined using the a-score and cross-validation methods provided by the adegenet package.

\section{Relatedness analysis}

We estimated pairwise genetic relatedness between all individuals using the $\mathrm{R}$ package related 1.0 (Pew et al. 2015). Performance of the 4 momentbased estimators available in this package was evaluated using the 'compareestimators' function, which uses Pearson's $r$ to correlate observed relatedness with simulated expected relatedness values. All 3 estimators had correlations near or above $90 \%$. Wang's estimator (Wang 2002) was marginally superior and therefore chosen for all further analyses. We also used the triadic likelihood estimator of Wang (2007), which uses a third control individual (triads instead of dyads), as an additional metric of pairwise relatedness. The triadic likelihood estimator was also used to compute inbreeding coefficients, with a $95 \%$ confidence interval, for each individual. To determine the power of our analysis to reject a null hypothesis of no relationship, we simulated 100 individuals for each of 4 relatedness classes (parent-offspring, fullsibling, half-sibling, unrelated) using empirically derived allele frequencies and calculated the range of expected relatedness values for each class.

Relatedness analyses are sensitive to genetic linkages between loci and population structure (Oliehoek et al. 2006, Wang 2007). Therefore, 1 locus was removed in any pair of loci that exhibited significant linkage. Linked loci in juvenile cod were removed only if the linkages were also observed in the adult populations, because transient genetic LD between loci may occur in recently settled cohorts of marine species (Hedgecock \& Pudovkin 2011). Given a general lack of population structure (see 'Results'), all adult cod from Newfoundland (Smith Sound, St. Mary's Bay, and Holyrood Pond) were pooled for relatedness analysis. Pooling does not affect the outcome of pairwise relatedness analyses between individuals, so long as allele frequencies remain similar after pooling. Juvenile cod genotypes were also pooled, for the same reason. In theory, selection also violates the assumptions of relatedness analyses, although some authors argue that such analyses are still useful, even in the presence of selection (Oliehoek et al. 2006). Therefore, we performed analyses both with and without loci showing significant departures from HWE.

Finally, we used group relatedness analysis to assess whether cod collected at each site were more related to each other on average than would be expected if all populations were randomly mating. This analysis compares mean observed relatedness in each group to expected relatedness derived from randomly shuffled individuals from all groups iteratively. Only adult cod from Newfoundland were subjected to this test because these samples alone had allele frequencies similar enough to suggest the possibility of random mating. Juvenile cod were also analyzed for group relatedness, across all sampling locations, and by bays, to see if they departed from random mating expectations. For each analysis, 5000 replicate iterations were computed.

\section{RESULTS}

Final sample sizes used for analysis included 364 adult genotypes and 671 juvenile genotypes. In the adults, the average number of alleles per locus across 72 loci was 15 (range: 3 to 52). There was also a large number of private alleles in each of the adult populations, from 12 at Ogac Lake to 95 at Georges Bank. The 15 loci used to genotype juveniles had an average of 28 alleles per locus (range: 16 to 39). We detected at least 1 private allele at all juvenile sampling sites, with a maximum of 13 at Dildo.

\section{Genetic diversity and population structure}

Across 72 loci and all adult samples, the overall cod population departed significantly from HWE $(p<$ 0.0001). The same was true for populations at each sampling site, across all loci. A total of 25 loci departed significantly from HWE in exact tests, or tests of heterozygote deficiency, in at least 1 or more adult sampling locations. Of the 9 non-EST-linked loci, 7 were in this group of 25 . Removing these 25 loci resulted in neutral expectations for all populations except Holyrood Pond, which continued to depart significantly from HWE across all loci, but not at any of the remaining loci individually. Across all 72 loci there was no significant correlation between the frequency of missing data and the frequency of homozygotes (Pearson's $r=0.18, p$-value $=0.07$ ); therefore, allele dropout was not a major contributor to departures 
from HWE. The full locus-by-locus and population-by-population summary statistics are available in Table S2 in the Supplement at www.int-res.com/ articles/suppl/m556p237_supp.xls.

Loci with significant heterozygote deficiencies may be experiencing directional selection, Wahlund effects, or may indicate inbreeding (Waples 2015). We cautiously reject Wahlund effects as a cause of HWE departure in adult cod because sample collections were geographically discrete, no populations were pooled for population-level analyses, and DAPC clustering algorithms were unable to describe more than 1 cluster per adult population, even when all principal components were retained for power. Given that $88 \%$ of these loci were EST-linked, we would expect some signal of selection. However, we find inbreeding better explains departures of HWE (see relatedness results).

Cod juveniles are not part of reproductive populations and cannot be expected to conform to HWE. However, on the whole, and somewhat counterintuitively, juveniles conformed better to HWE than did adults at the same loci. Whereas all adult sampling locations departed significantly from HWE across all loci, half of the juvenile sites did not. The relatively high allelic diversity at all juvenile sample sites was comparable to adult populations in all cases (Table 1). Moreover, juveniles on the whole showed less LD than the adult cod (Fig. 2) and exhibited different patterns of linkage (only 1 pair of loci was shown to be linked in both adults and juveniles), at the same 15 loci. This pattern was seen both in pooled juveniles and for each juvenile sampling site. There was much less correlation between the frequency of missing data and homozygotes in the juvenile dataset (Pearson's $\mathrm{r}=-0.28$, p-value $=0.9$ ) than was seen in the adults, suggesting that increased homozygosity is a biological signal, and not due to PCR artefacts, such as allele dropout.

All adult sample sites were significantly differentiated using conventional pairwise $F_{\mathrm{ST}}$ analysis (Fig. 3). However, the population structure detected among Smith Sound, St. Mary's Bay, and Holyrood Pond
Table 1. Summary statistics for 72 microsatellite loci from Atlantic cod adults, subset of 15 loci for adults and juveniles: population name, number of individuals (n), numbers of loci and alleles, sample size independent allelic richness $\left(A_{R}\right)$, observed and expected heterozygosity $\left(H_{\mathrm{o}}\right.$ and $\left.H_{\mathrm{e}}\right)$, Weir and Cockerham's $F_{\text {IS }}$ across all loci, the number of loci that significantly depart from HardyWeinberg expectations using an exact test (HWE), and the number of loci per population that exhibit significant heterozygote deficit $\left(H_{\text {Def }}\right)$. Adjusting the $\mathrm{p}$-value threshold to $\alpha=0.05$, multiple hypothesis testing in the last 2 variables was accomplished using the false discovery rate of Benjamini et al. (2006)

\begin{tabular}{|c|c|c|c|c|c|c|c|c|c|}
\hline Population & $\mathrm{n}$ & Loci & Alleles & $A_{\mathrm{R}}$ & $H_{\mathrm{o}}$ & $H_{\mathrm{e}}$ & $F_{\mathrm{IS}} \quad \mathrm{I}$ & HWE & $H_{\text {Def }}$ \\
\hline \multicolumn{10}{|l|}{ Adults } \\
\hline Ogac Lake & 60 & $\begin{array}{l}72 \\
15\end{array}$ & $\begin{array}{l}355 \\
115\end{array}$ & $\begin{array}{l}4.6 \\
3.81\end{array}$ & $\begin{array}{l}0.5 \\
0.68\end{array}$ & $\begin{array}{l}0.52 \\
0.7\end{array}$ & $\begin{array}{l}0.0254 \\
0.0287\end{array}$ & $\begin{array}{l}9 \\
7 \\
7\end{array}$ & $\begin{array}{l}8 \\
2\end{array}$ \\
\hline \multirow[t]{2}{*}{ Gilbert Bay } & 61 & 72 & 475 & 6.07 & 0.57 & 0.59 & 0.028 & 3 & 8 \\
\hline & & 15 & 153 & 4.67 & 0.75 & 0.77 & 0.0337 & 7 & 1 \\
\hline \multirow[t]{2}{*}{ Smith Sound } & 62 & 72 & 755 & 9.26 & 0.62 & 0.65 & 0.0362 & 3 & 6 \\
\hline & & 15 & 251 & 5.93 & 0.86 & 0.88 & 0.0225 & 50 & 2 \\
\hline \multirow[t]{2}{*}{ St. Mary's Bay } & 61 & 72 & 742 & 9.13 & 0.61 & 0.64 & 0.0456 & 5 & 8 \\
\hline & & 15 & 265 & 5.96 & 0.84 & 0.86 & 0.0295 & 52 & 3 \\
\hline \multirow[t]{2}{*}{ Holyrood Pond } & 58 & 72 & 720 & 9 & 0.62 & 0.65 & 0.0393 & 7 & 7 \\
\hline & & 15 & 241 & 6 & 0.83 & 0.87 & 0.04 & 2 & 3 \\
\hline \multirow[t]{2}{*}{ Georges Bank } & 62 & 72 & 761 & 9.35 & 0.63 & 0.64 & 0.0176 & 4 & 3 \\
\hline & & 15 & 259 & 5.98 & 0.86 & 0.86 & -0.0028 & 30 & 2 \\
\hline \multicolumn{10}{|l|}{ Juveniles } \\
\hline Indian Bay & 49 & 15 & 228 & 5.3 & 0.79 & 0.86 & 0.0851 & 2 & 5 \\
\hline Newman Sound & 42 & 15 & 212 & 5.38 & 0.87 & 0.86 & -0.006 & 0 & 0 \\
\hline Bread Cove & 42 & 15 & 222 & 5.4 & 0.84 & 0.87 & 0.0314 & 1 & 2 \\
\hline Cannings Cove & 49 & 15 & 236 & 5.66 & 0.85 & 0.88 & 0.0274 & 0 & 1 \\
\hline Smith Sound & 50 & 15 & 234 & 5.6 & 0.84 & 0.86 & 0.019 & 0 & 0 \\
\hline Mosquito Cove & 45 & 15 & 234 & 5.66 & 0.84 & 0.87 & 0.0395 & 50 & 3 \\
\hline Woody Island & 15 & 15 & 159 & 5.36 & 0.85 & 0.85 & 0.0008 & 0 & 0 \\
\hline Harbour Grace & 39 & 15 & 224 & 5.29 & 0.83 & 0.86 & 0.0382 & 0 & 4 \\
\hline St. Bernard's Cove & 44 & 15 & 218 & 5.28 & 0.85 & 0.86 & 0.0086 & 1 & 0 \\
\hline Great Brule & 48 & 15 & 229 & 5.66 & 0.86 & 0.87 & 0.0035 & 50 & 2 \\
\hline Bristol Hope & 5 & 15 & 90 & 4.49 & 0.85 & 0.79 & -0.0762 & 0 & 0 \\
\hline Dildo & 52 & 15 & 259 & 5.83 & 0.86 & 0.88 & 0.0228 & 2 & 2 \\
\hline Holyrood Beach & 43 & 15 & 222 & 5.72 & 0.84 & 0.87 & 0.0339 & 0 & 1 \\
\hline Harbour Buffett & 32 & 15 & 175 & 4.73 & 0.8 & 0.85 & 0.0533 & 0 & 0 \\
\hline Spanish Room & 26 & 15 & 194 & 5.18 & 0.82 & 0.85 & 0.0328 & 1 & 1 \\
\hline Tappers Cove & 45 & 15 & 230 & 5.45 & 0.83 & 0.86 & 0.0369 & 0 & 1 \\
\hline Colinet Island & 36 & 15 & 214 & 5.31 & 0.85 & 0.86 & 0.0054 & 0 & 0 \\
\hline Trepassey & 9 & 15 & 119 & 4.56 & 0.82 & 0.8 & -0.0247 & 70 & 0 \\
\hline
\end{tabular}

(Newfoundland sites) was shallow $\left(F_{\mathrm{ST}}=\sim 0.005\right)$, typical of inshore cod in previous population genetic studies (Knutsen et al. 2004, 2011). In contrast, Newfoundland sites were not significantly differentiated using $D_{\text {EST }}$ (Fig. 3). For the juveniles, pairwise $F_{\mathrm{ST}}$ revealed no meaningful pattern of structure, in spite of private alleles, and no signal of isolation-by-distance was detected. Likewise, we found no detectable relationship between pairwise genetic differentiation and envi- 
Linkage disequilibrium
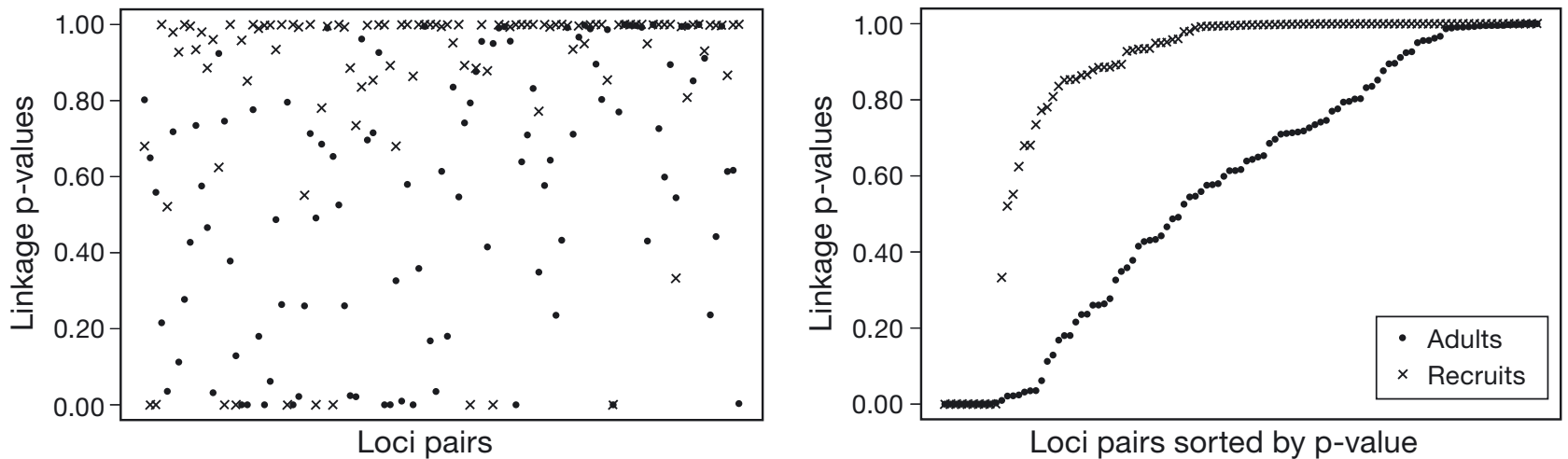

Fig. 2. Sorted and unsorted p-values for overall pairwise linkage disequilibrium among 15 microsatellite loci for adult and juvenile Atlantic cod

\section{A}

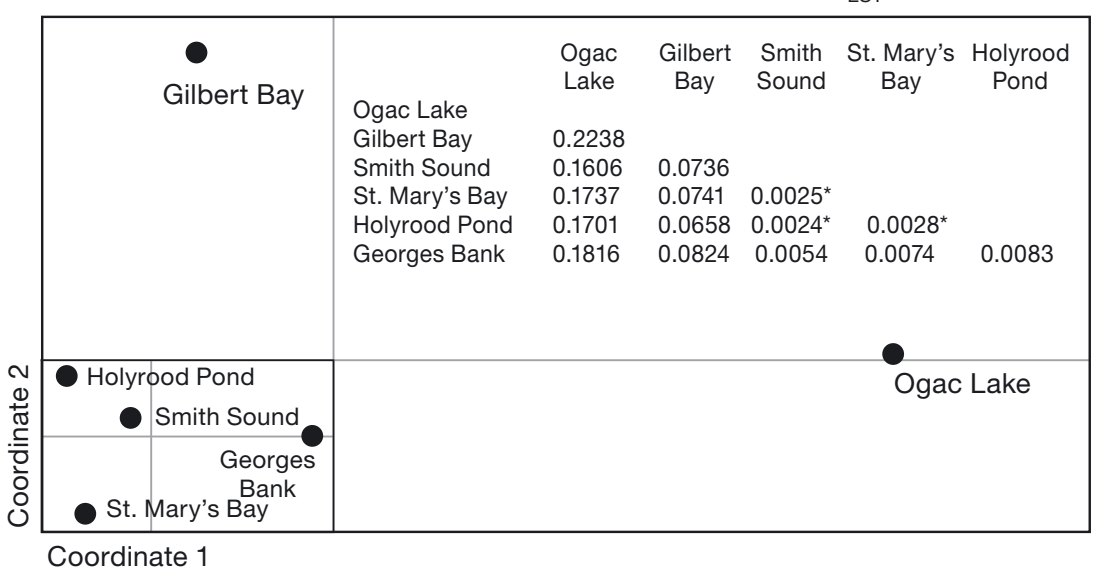

$\mathrm{B}$

Principal coordinates, pairwise $F_{\mathrm{ST}}$

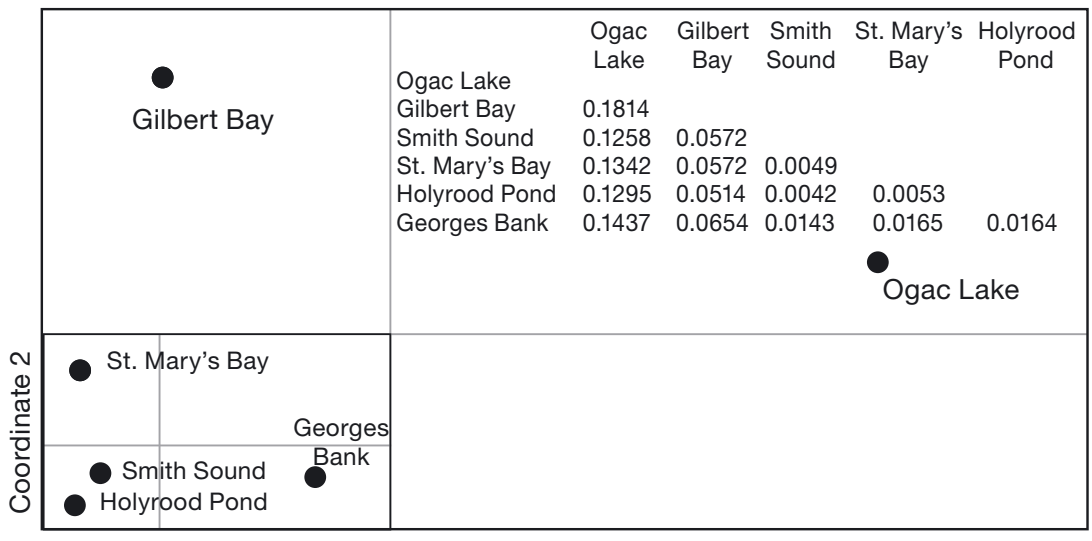

Coordinate 1

Fig. 3. Pairwise population structure of 6 adult Atlantic cod populations from the west Atlantic, using 72 microsatellite loci. (A) Principal coordinates of pairwise $D_{\text {EST }}$ values. Southern sampling locations are separated into the lower left quadrant and have been plotted separately for clarity. Raw values are imbedded in the upper right quadrant. ${ }^{*}$ Not statistically significant. (B) Principal coordinates of pairwise $F_{\mathrm{ST}}$ values ronmental variables at each sample site. Overall, cod juveniles lacked conspicuous spatial signals and no significant differentiation was observed between any pair of juvenile sample sites when using $D_{\mathrm{EST}}$ as the fixation index (Fig. 4).

\section{Discriminant analysis of principal components}

Multivariate analyses of population genetic data, such as DAPC, do not assume HWE, or selective neutrality, and are insensitive to LD. Therefore, no loci were omitted for this analysis. For the adult data set of 72 loci, the optimal number of principal components to retain was 90 , comprising about $68 \%$ of the conserved genetic variation. Organizing the adult genotypes by geographic sample site effectively described genetic patterns in multivariate space, with over $72 \%$ of individuals being assigned to their site of origin. Ogac Lake and Gilbert Bay had 100\% assignment rates, were each differentiated on separate axes, and the distinction of these 2 populations was by far the strongest signal in the data. When Ogac Lake and Gilbert Bay cod were removed from the analysis, assignment rates among the 


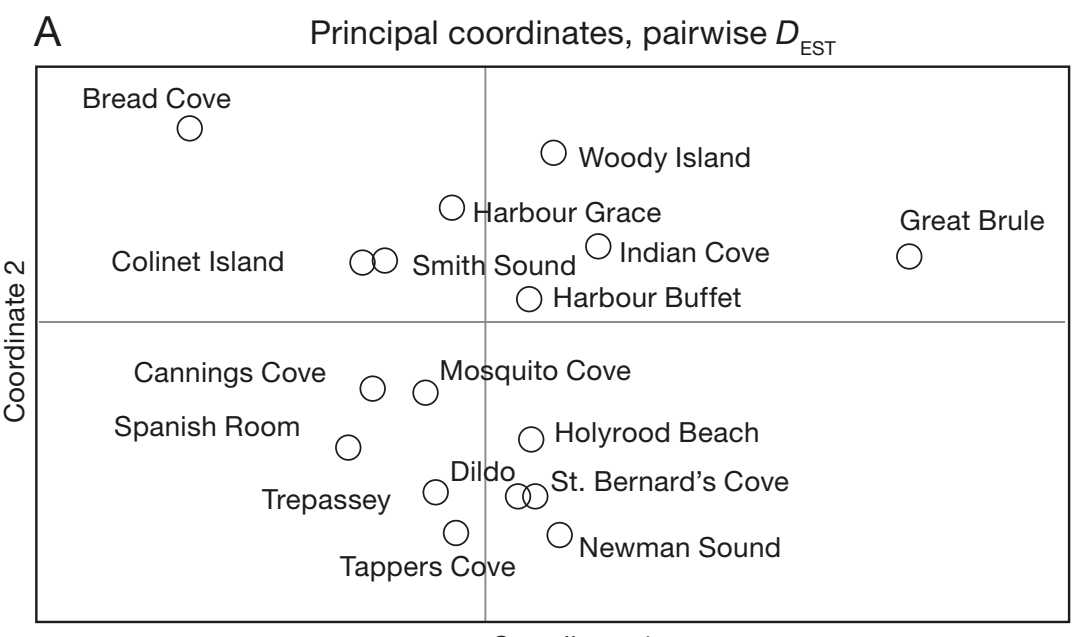

Coordinate 1

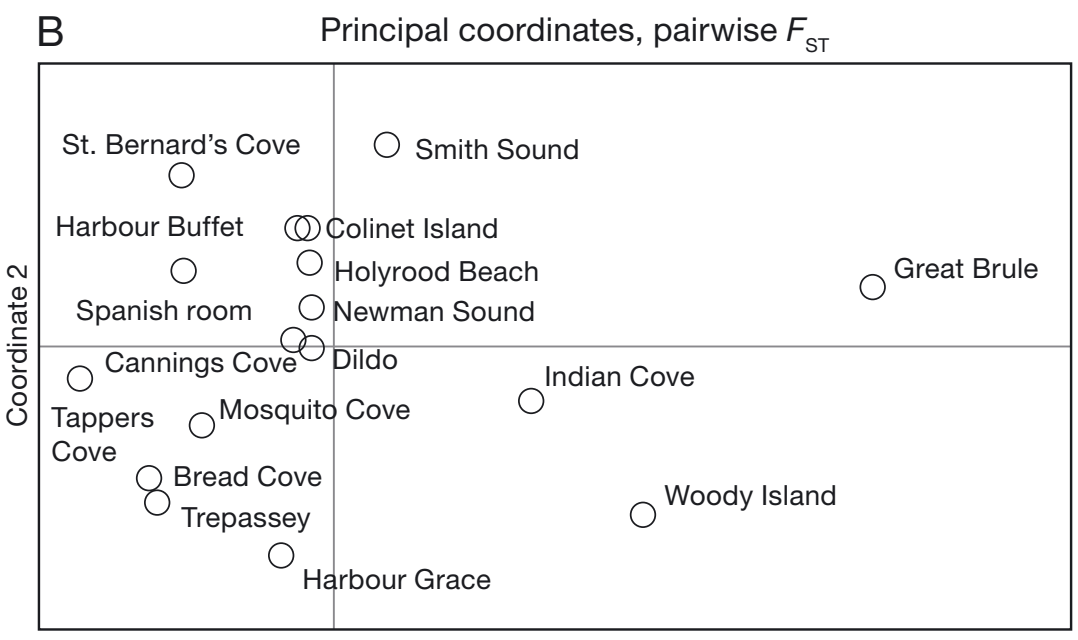

Coordinate 1

Fig. 4. Pairwise population structure of 18 sampling locations of juvenile Atlantic cod from eastern Newfoundland, using 15 microsatellite loci. (A) Principal coordinates of pairwise $D_{\text {EST }}$ values. No pairwise values were statistically significant. (B) Principal coordinates of pairwise $F_{\mathrm{ST}}$ values. Only 12 out of 153 pairwise values were significant (mean significant $\left.F_{\mathrm{ST}}=0.0096\right)$, but did not show a geographic pattern

other sites improved to $87 \%$ overall, ranging from a low of $78 \%$ for St. Mary's Bay to a high of $98 \%$ for Georges Bank (Fig. 5).

Unlike the adult populations, which were easily distinguished in only 2 dimensions using less than $70 \%$ of the available variance, juveniles were more difficult to distinguish by their geographic sampling locations. However, this might be expected, given the denser geographic sampling of juveniles than adults. The optimal number of principal components to retain for the juvenile dataset of 15 loci and 18 sites was 220, comprising about $98 \%$ of the conserved variation, and 10 axes were needed to assign individuals to their locations of origin at a rate of $73 \%$ accuracy. In spite of the power of this analysis to discriminate between juvenile sampling sites, whether such small multivariate distances amount to a biologically meaningful pattern appears doubtful. Using $k$-means clustering to group the juvenile genotypes without a priori population labels suggests that 4 to 6 clusters represent a better population model than 18 geographic locations (results not shown). Each of these inferred clusters occurred at all sampling sites but their biological significance, if any, is not known. Generally, the results of DAPC analysis for cod juveniles were inconclusive.

Following DAPC of adult cod, we calculated the loading values of each allele, to determine which loci contributed most to the population discrimination. A total of 48 alleles had loading values greater than 0.01 , and 16 alleles had values greater than 0.02 across all adult populations. For Newfoundland and Georges Bank populations only, 43 alleles had loading values greater than 0.01 , and 13 had values above 0.02 . Loading values are given in Table S3. Loci showing significant departures from HWE did not have disproportionately high loading values, but loading values were correlated with the number of alleles in each locus (Pearson's $\mathrm{r}=$ $0.70, \mathrm{p}<2 \times 10^{-11}$ ). Of the subset of 15 loci used to genotype juveniles, 11 had alleles with high loading values.

Reducing the adult data set to 15 loci resulted in only a minor loss of discriminatory power, with assignment rates between 65 and $85 \%$ for all populations, with $60 \%$ of the conserved variation retained. Therefore, differences in the number of loci used cannot explain the disparate patterns between juveniles and adult cod.

\section{Relatedness}

Relatedness analyses can vary unpredictably in performance from organism to organism, and are generally notorious for Type I errors in natural populations (Taylor 2015 and references therein). However, our goal was not to identify all probable kinship 


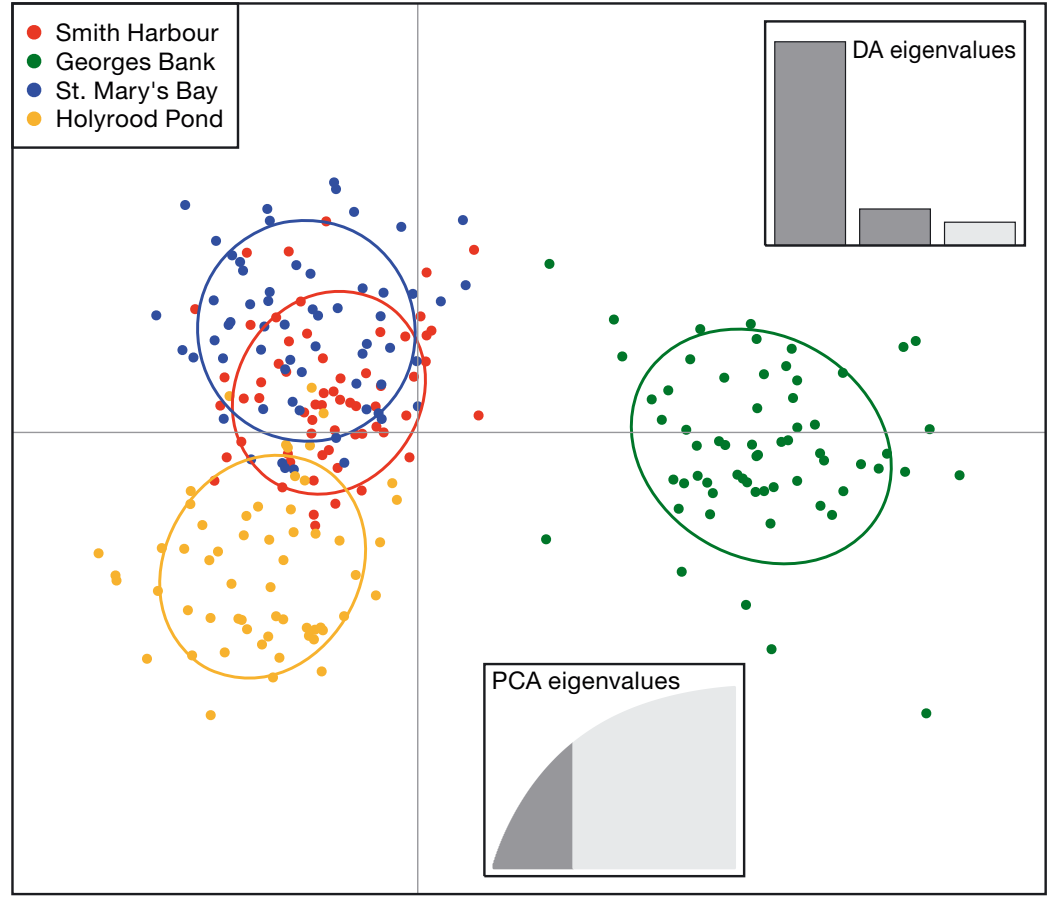

Fig. 5. Discriminant analysis of principal components (DAPC) scatterplot of adult Atlantic cod genotypes. The proportion of principal component eigenvalues retained as predictors for linear discriminant analysis (DA; bottom right corner) is highlighted in dark grey. A total of 80 principal components were retained, comprising $69 \%$ of the conserved genetic variation in the loci. The first 2 DA eigenvalues (upper right corner) are highlighted in dark grey and correspond to the the horizontal and vertical axes, respectively. The proportion of individuals assigned to their population of origin was $88 \%$ locus. The reasoning behind this penalty was to reduce high values in dyads where combinations of missing data among individuals left few loci to determine relatedness.

We detected statistically significant relatedness in 5 pairs of adult cod in 3 of the 6 sampling locations, but none between sampling locations (Table 2, Fig. 6). None of the individuals in these dyads were indicated as being inbred. Only 2 pairs of juveniles had a statistically significant relatedness value: one within Bread Cove and another shared between Harbour Grace and Great Brule (Table 2). This second juvenile dyad had a perfect correlation of alleles at 12 heterozygous loci, suggesting a high degree of relatedness, in spite of being separated by an over-water distance of $>500 \mathrm{~km}$. Furthermore, the 2 sample sites are located in different Northwest Atlantic Fisheries Organization (NAFO) divisions (3L and 3Ps, respectively).

Using only the 45 loci that did not depart from HWE, we detected only 1 adult individual with a significant genetic signature of inbreeding. This individual was from Holyrood Pond, a location that was also shown to depart pairs, but rather to assess whether evidence of family structures exists within populations of adult or juvenile cod. For this reason we opted for strict significance criteria. According to our simulations, mean relatedness values in unrelated adult cod are not likely to be greater than 0.24 for Wang's relatedness estimator, or 0.14 for the triadic likelihood estimator. Therefore, we suggest that a lower $95 \%$ confidence interval above these values, in both estimators, is sufficient to reject a null hypothesis of no relationship. For point estimates of pairwise adult relatedness, 7 loci were initially removed for linkages. Analyses were then repeated with 20 additional loci removed due to departure from HWE.

For juveniles, our significance criteria were stricter ( 0.25 and 0.20 for the 2 relatedness estimators, respectively). Additionally, because our analysis included only 13 unlinked juvenile loci, we imposed penalties on juvenile dyads for missing data. There is no convention for dealing with missing data in kinship analyses. However, for our purposes, we raised the lower 95\% confidence interval criterion by 0.1 for every missing from HWE even after all loci with significant departures were removed. However, with all 65 non-linked loci included, inbred individuals were indicated for all adult sampling locations; St. Mary's Bay had the most with 5, and Smith Sound the least with 1. Inbreeding can be a cause of heterozygote deficit and may explain why over one-third of the loci in this study departed from HWE, and why these loci were not predominantly EST-linked. Inbreeding might also explain the higher level of genetic linkage between loci in adult populations (Fig. 2). Only 1 juvenile cod, from Harbour Grace, possessed a signal of inbreeding, and the small lower $95 \%$ confidence interval (0.0006) suggests that this inference is highly questionable.

A total of 5000 randomizations of group relatedness, using 65 loci, indicate that adult cod from St. Mary's Bay were more related on average $(\mathrm{p}<$ 0.042 ) than would be expected if all populations were randomly mating (Fig. 6). Cod adults from Smith Sound were not more related than expected with the full set of 65 loci, but when the 20 loci with HWE departures were excluded, the pattern changed and 
Table 2. Atlantic cod dyads with significant relatedness values for both the Wang and triadic (trioML) likelihood estimators (with $95 \%$ confidence intervals shown in parentheses) and the number of loci with missing data $\left(\mathrm{N}_{2}\right)$. Full siblings are expected to have relatedness values of $\sim 0.5$, on average, but can range from 0.0 to 1.0

\begin{tabular}{|c|c|c|c|c|c|c|}
\hline & Individual 1 & Individual 2 & Loci & Wang & TrioML & $\mathrm{N}_{?}$ \\
\hline \multirow[t]{5}{*}{ Adults } & St. Mary's Bay 385 & St. Mary's Bay 389 & 45 & $\begin{array}{c}0.923 \\
(0.808-1.000)\end{array}$ & $\begin{array}{c}0.896 \\
(0.788-1.000)\end{array}$ & 8 \\
\hline & St. Mary's Bay 464 & St. Mary's Bay 468 & 45 & $\begin{array}{c}0.846 \\
(0.657-0.956)\end{array}$ & $\begin{array}{c}0.857 \\
(0.684-0.984)\end{array}$ & 8 \\
\hline & Holyrood Pond 481 & Holyrood Pond 485 & 45 & $\begin{array}{c}0.921 \\
(0.821-0.984)\end{array}$ & $\begin{array}{c}0.907 \\
(0.809-0.968)\end{array}$ & 3 \\
\hline & Holyrood Pond 516 & Holyrood Pond 520 & 45 & $\begin{array}{c}0.82 \\
(0.679-0.930)\end{array}$ & $\begin{array}{c}0.773 \\
(0.640-0.908)\end{array}$ & 7 \\
\hline & Georges Bank 101 & Georges Bank 128 & 45 & $\begin{array}{c}0.414 \\
(0.268-0.563)\end{array}$ & $\begin{array}{c}0.354 \\
(0.200-5.000)\end{array}$ & 8 \\
\hline \multirow[t]{2}{*}{ Juveniles } & Bread Cove 792 & Bread Cove 794 & 13 & $\begin{array}{c}0.759 \\
(0.489-1.000)\end{array}$ & $\begin{array}{c}0.812 \\
(0.533-1.000)\end{array}$ & 2 \\
\hline & Harbour Grace 39 & Great Brule 51 & 13 & $\begin{array}{c}1.000 \\
(1.000-1.000)\end{array}$ & $\begin{array}{c}1.000 \\
(1.000-1.000)\end{array}$ & 1 \\
\hline
\end{tabular}

mean group relatedness within Smith Sound increased ( $\mathrm{p}<0.054$; Fig. 6). In contrast, excluding loci had the opposite effect on St. Mary's Bay cod, decreasing observed relatedness to close-to-expected values. Observed group relatedness in Holyrood Pond cod remained near expected values regardless of how many loci were used. When the adult cod data were reduced to the subset of 15 loci used for typing juveniles, St. Mary's Bay cod were again more related on average than expected ( $p<0.031)$, but the other 2 populations were not. Therefore, this analysis appears to be more sensitive to departures from HWE than absolute numbers of loci.

Fig. 6. Boxplots of pairwise relatedness estimates for adult cod from Newfoundland (A) using 65 unlinked microsatellite loci and (B) using the 45 loci that do not depart from Hardy-Weinberg expectations. Outliers with statistically significant kinship relationships (i.e. full siblings) are shown (+). Dashed grey lines are the mean relatedness estimates reported from 5000 randomizations and represent random mating expectations among all locations. p-values represent the probability of falsely rejecting a null hypothesis of random mating with the other populations
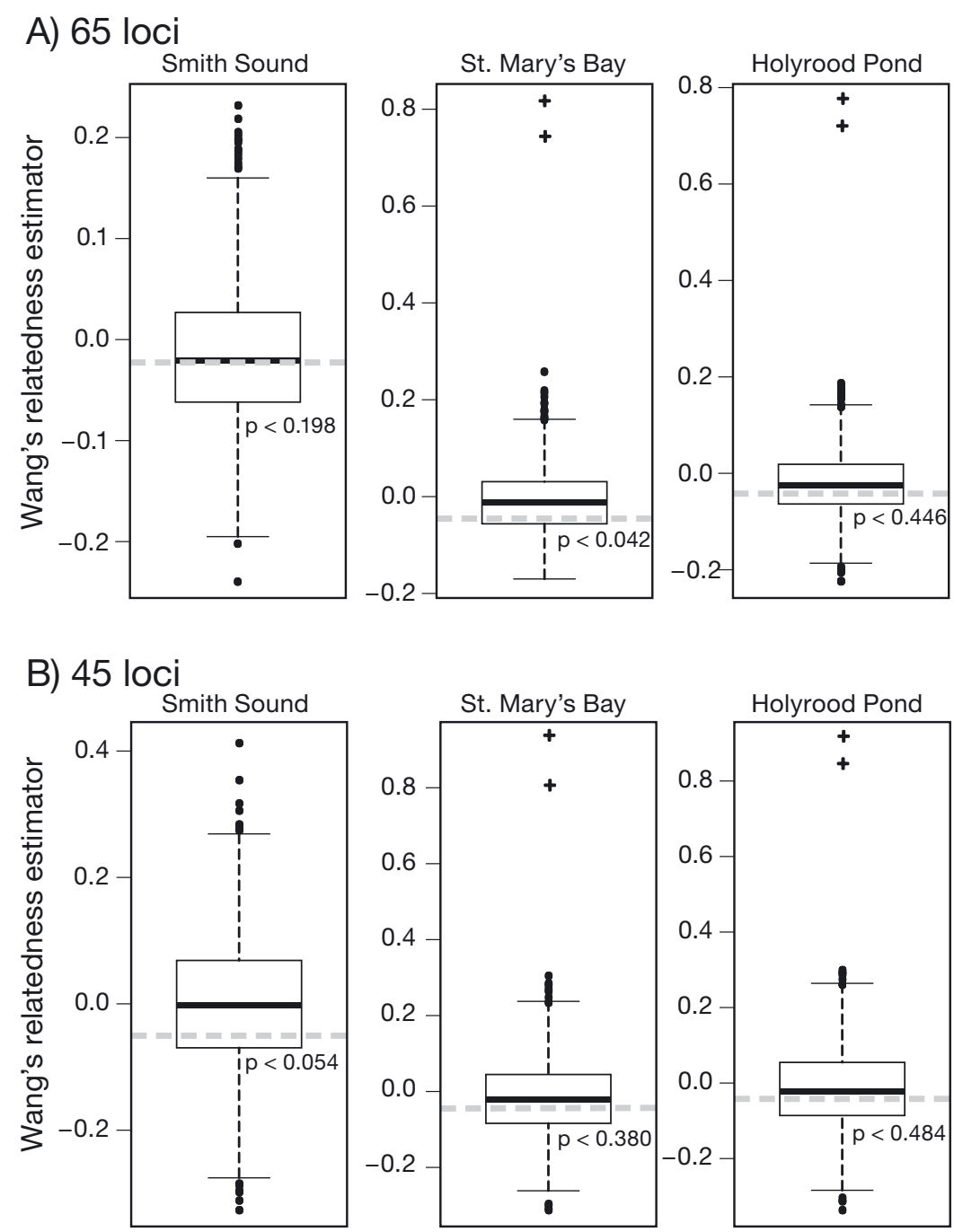

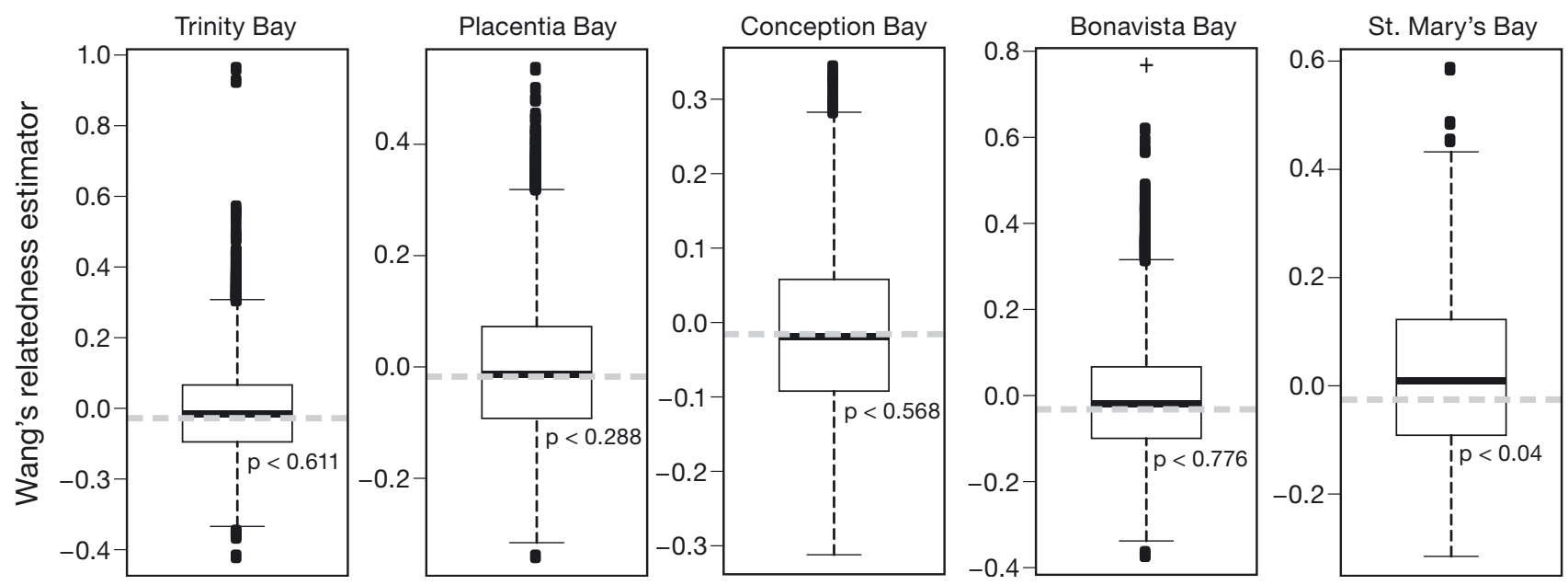

Fig. 7. Boxplots of pairwise relatedness estimates for juvenile Atlantic cod from Newfoundland bays. Estimates are based on 13 unlinked loci. Outliers with statistically significant kinship relationships (i.e. full siblings) are shown (+). Dashed grey lines are the mean relatedness estimates reported from 5000 randomizations of all individuals in the dataset and represent random mating expectations among all locations. p-values represent the probability of falsely rejecting a null hypothesis of random mating among populations

Mean group relatedness deviated from random expectations in only 1 out of 18 groups of juveniles: Colinet Island (St. Mary's Bay; Fig. 7). Colinet Island was the only juvenile sample from St. Mary's Bay. The Trepassey sample was collected just outside the bay, and when combined with Colinet Island fish, the group was no less random than other groups (individually or when pooled by bay), suggesting a finescale pattern of relatedness inside St. Mary's Bay.

\section{DISCUSSION}

Populations can be highly connected by gene flow across evolutionary time and yet have no demographically significant migrant exchange in recent generations (Waples \& Gaggiotti 2006, Lowe \& Allendorf 2010). Mean relatedness estimates in some demersal marine populations, e.g. spiny lobster Panulirus argus (Iacchei et al. 2013) and dogtooth tuna Gymnosarda unicolor (Bentley et al. 2014), have revealed cohesive family structures at local spatial scales, suggesting demographic discontinuities between geographic locations that are otherwise connected by high levels of gene flow. Our results indicate that localized family structures can also exist in adult populations of Atlantic cod. The presence of these family structures alone does not preclude the possibility of demographically significant migrant exchange, because closely related individuals might comprise only a component of the population. However, collections of juvenile cod displayed far less family structuring, more genetic homogeneity, and less genetic linkage than adults (Figs. 2, 4 \& 7). Therefore, elevated local relatedness in adult cod along coastal Newfoundland is not likely driven by dispersal limitations during the pelagic larval phase, but rather by post-larval processes.

Kinship relationships are commonly detected in larval and juvenile marine fishes (Planes et al. 2002, Buston et al. 2009, Bernardi et al. 2012, Horne et al. 2013). Cohorts of larval cod, captured from plankton tows, have also been shown to be the progeny of few adults (Ruzzante et al. 1996; but see Herbinger et al. 1997). Being the first post-larval relatedness study for this species, we consider our results exploratory. But provisionally it appears that adult cod tend to live in close proximity with kin, whereas age-0 juvenile kin are distributed across wider spatial scales. Blouin (2003) argues that with 30 or more microsatellite loci, relatedness can be estimated with confidence (see also Harrison et al. 2013). Therefore, our inferences of pairwise relatedness in adult cod are likely robust. Putative sibling pairs identified in juvenile samples were based on only 13 loci, but these were among the most polymorphic and informative loci in the study. Additionally, our simulated models of relatedness in juvenile cod suggest these inferences are unlikely to be Type I errors. Note, however, that the stricter criteria used to determine significant relatedness in juvenile cod might increase the Type II error rate relative to the adults.

If these juvenile dyads are true siblings, it seems improbable that they were sampled from a random 
mix of offspring. More likely, there is reproductive skew in the population, where some spawning pairs are contributing disproportionately to young-of-theyear cod. Size, fecundity, and other maternal effects are likely to be factors (Johnson et al. 2011, Beldade et al. 2012). Stochastic larval survivorship among egg clutches (i.e. reproductive sweepstakes) is another explanation (Hedgecock \& Pudovkin 2011). Yet, if any of these processes were pervasive, we might expect to see more LD and less allelic diversity in juvenile cohorts, relative to adults, than were observed in the data. Therefore, expected patterns of allelic diversity and LD associated with reproductive skew must be masked by extensive admixture of juvenile cod across long stretches of coastline. The 4 to 6 broadly distributed genetic clusters of juveniles revealed by $k$-means clustering (see 'Results: Discriminant analysis of principal components') may be suggestive of this mixing. Indeed, LD analyses of 5 juvenile $k$-means clusters in GENEPOP revealed more linkage than were observed in adults (data not shown), suggesting both sweepstakes like processes and admixture.

Our data indicate that local populations of inshore Newfoundland cod experience shifts in genetic patterns between the time they settle as juveniles and adulthood. One cause of these shifts might be random genetic drift, owing to natural mortality across life stages. However, genetic drift cannot account for local family structures. Another likely possibility is that, at some point after the pelagic larval stage, admixed populations of juvenile cod sort into inshore and offshore ecotypes (André et al. 2016, Bonanomi et al. 2016). Cod larvae from offshore spawning areas are often transported by ocean currents into nearshore areas (Pepin \& Helbig 1997), where they may reside as juveniles. In the northeastern Atlantic, as many as $10 \%$ of recruiting cod in the Skagerrak Strait are migrants from offshore areas in the North Sea (Knutsen et al. 2004, Stenseth et al. 2006), enough to have an impact on population size and persistence (Waples \& Gaggiotti 2006, Lowe \& Allendorf 2010). Yet, cod spend up to 4 yr as juveniles and many progressively seek deeper habitats as they mature (Dalley \& Anderson 1997). If these migrant juveniles eventually transition into offshore cod, then their dispersal as larvae would not result in migrant exchange among inshore and offshore populations.

Local adaptation can also prevent connectivity through non-random mortality of poorly adapted dispersers (Marshall et al. 2010), or by promoting secondary dispersal in post-larval stages. In recent years, cod has become a model marine organism for studying local adaptation. Research now shows that cod have genetic polymorphisms associated with temperature (Bradbury et al. 2010, 2013), salinity (Berg et al. 2015), and different light environments (Pampoulie et al. 2015). Thus, there may be nearshore sorting among juvenile cod that leave nursery areas in search of optimal adult habitat. Cod from Labrador and northeastern Newfoundland, for example, inhabit colder waters and are often considered a single stock (2J3KL), relative to fish from southern Newfoundland and the northern Gulf of St. Lawrence (Templeman 1974, Brattey et al. 2008; see also Campana et al. 1999). Yet, in this study, we detected a putative full-sibling relationship separated on opposite sides of Newfoundland, and across management divisions (Table 2). This result suggests that the offspring from a single spawning pair may disperse widely as larvae, but this dispersal does not result in population connectivity if the migrant sibling suffers non-random mortality, or makes a return migration to natal waters as a sub-adult.

Mean group relatedness among juvenile cod in our study conformed to random mating expectations, with 1 exception. Juvenile cod from St. Mary's Bay were more related than average, compared to collections from other bays (Fig. 7). This result might be taken as support for the larval retention hypothesis (Bradbury et al. 2000, Nielsen et al. 2005, Myksvoll et al. 2011). Presumably, locally adapted cod that recruit to natal habitats are likely to complete their life cycle in the same area as their parents. The significant mean group relatedness of adult cod in St. Mary's Bay is also evidence that this inshore population is sedentary and may be sustained through some degree of self-recruitment. However, year-toyear variation in small-scale oceanographic conditions might make self-recruitment temporally unstable (Knutsen et al. 2004, Nielsen et al. 2005). Some level of inbreeding in St. Mary's Bay (and other populations) is similarly suspected, given departures from HWE. Forces like selection and inbreeding do not act uniformly across the genome (Nosil et al. 2009, Kardos et al. 2015), so it is not entirely unexpected that only $35 \%$ of the loci departed significantly from HWE in the face of widespread inbreeding. In the present study we were not able to assign juvenile genotypes to adult populations to verify relationships between adult and age-0 juvenile cod in St. Mary's Bay. However, we have shown that significant genetic relationships are detectable among adult and juvenile cod, laying the groundwork for future relatedness studies on this species. 


\section{CONCLUSIONS}

The relatedness analyses presented here are the first of their kind for this species and clearly show that individual relatedness is a detectable signal in post-larval cod. Patterns suggest that larval dispersal may be less important to population connectivity than post-larval processes in Atlantic cod. While not all pelagic dispersing marine species have post-larval stages capable of dispersal, for cod these data may help reconcile the conundrum of population structure in spite of highly dispersive pelagic larvae.

Acknowledgements. The research was funded by a Natural Sciences and Engineering Research Council of Canada (NSERC) Strategic Projects Grant led by P.V.R.S., NSERC Discovery Grant to P.B., Fisheries \& Oceans Canada (DFO) Species at Risk funding led by R.S.G., and NOAA National Marine Fisheries Service Grant for a workshop to B.J.L. Assistance with field collections was variously provided on Georges Bank by Patrick O'Reilly, and on the Island of Newfoundland by Mervin Langdon and Margaret Warren. The manuscript was reviewed and improved by comments of 2 anonymous reviewers.

\section{LITERATURE CITED}

André C, Svedäng H, Knutsen H, Dahle G and others (2016) Population structure in Atlantic cod in the eastern North Sea-Skagerrak-Kattegat: early life stage dispersal and adult migration. BMS Res Notes 9:63

> Beldade R, Holbrook SJ, Schmitt RJ, Planes S, Malone D, Bernardi G (2012) Larger female fish contribute disproportionately more to self-replenishment. Proc R Soc B 279:2116-2121

Benjamini Y, Krieger AM, Yekutieli D (2006) Adaptive linear step-up procedures that control the false discovery rate. Biometrika 93:491-507

Bentley BP, Harvey ES, Newman SJ, Welch DJ, Smith AK, Kennington WJ (2014) Local genetic patchiness but no regional differences between Indo-West Pacific populations of the dogtooth tuna Gymnosarda unicolor. Mar Ecol Prog Ser 506:267-277

> Bentzen P, Taggart CT, Ruzzante DE, Cook D (1996) Microsatellite polymorphism and the population structure of Atlantic cod (Gadus morhua) in the northwest Atlantic. Can J Fish Aquat Sci 53:2706-2721

Berg PR, Jentoft S, Star B, Ring KH and others (2015) Adaptation to low salinity promotes genomic divergence in Atlantic cod (Gadus morhua L.). Genome Biol Evol 7: 1644-1663

- Bernardi G, Beldade R, Holbrook SJ, Schmitt RJ (2012) Fullsibs in cohorts of newly settled coral reef fishes. PLoS ONE 7:e44953

Blouin MS (2003) DNA-based methods for pedigree reconstruction and kinship analysis in natural populations. Trends Ecol Evol 18:503-511

Bonanomi S, Therkildsen NO, Retzel A, Hedeholm RB and others (2016) Historical DNA documents natal homing in marine fish. Mol Ecol 25:2727-2734

Bradbury IR, Snelgrove PVR, Fraser S (2000) Transport and development of eggs and larvae of Atlantic cod, Gadus morhua, in relation to spawning time and location in coastal Newfoundland. Can J Fish Aquat Sci 57: 1761-1772

$>$ Bradbury IR, Hubert S, Higgins B, Borza T and others (2010) Parallel adaptive evolution of Atlantic cod on both sides of the Atlantic Ocean in response to temperature. Proc R Soc B 277:3725-3734

Bradbury IR, Hubert S, Higgins B, Bowman S and others (2013) Genomic islands of divergence and their consequences for the resolution of spatial structure in an exploited marine fish. Evol Appl 6:450-461

Brattey J, Healey BP, Porter DR (2008) Northern cod (Gadus morhua) 16 years after the moratorium: new information from tagging and acoustic telemetry. Canadian Science Advisory Secretariat Research Document 2008/047. Fisheries and Oceans Canada, St. John's

Burgess SC, Nickols KJ, Griesemer CD, Barnett LA and others (2014) Beyond connectivity: how empirical methods can quantify population persistence to improve marine protected-area design. Ecol Appl 24:257-270

> Buston PM, Fauvelot C, Wong MYL, Planes S (2009) Genetic relatedness in groups of the humbug damselfish Dascyllus aruanus: small, similar-sized individuals may be close kin. Mol Ecol 18:4707-4715

Campana SE, Chouinard GA, Hanson JM, Frechet A (1999) Mixing and migration of overwintering Atlantic cod (Gadus morhua) stocks near the mouth of the Gulf of St. Lawrence. Can J Fish Aquat Sci 56:1873-1881

COSEWIC (2010) COSEWIC assessment and status report on the Atlantic cod (Gadus morhua) in Canada. Committee on the Status of Endangered Wildlife in Canada, Ottawa

Cowen RK, Sponaugle S (2009) Larval dispersal and marine population connectivity. Annu Rev Mar Sci 1:443-466

Dalley EL, Anderson JT (1997) Age-dependent distribution of demersal juvenile Atlantic cod (Gadus morhua) in inshore/offshore northeast Newfoundland. Can J Fish Aquat Sci 54:168-176

Elphinstone MS, Hinten GN, Anderson MJ, Nock CJ (2003) An inexpensive and high-throughput procedure to extract and purify total genomic DNA for population studies. Mol Ecol Notes 3:317-320

Goslee SC, Urban DL (2007) The ecodist package for dissimilarity-based analysis of ecological data. J Stat Softw 22: $1-19$

- Gotceitas V, Fraser S, Brown JA (1997) Use of eelgrass beds (Zostera marina) by juvenile Atlantic cod (Gadus morhua). Can J Fish Aquat Sci 54:1306-1319

> Harrison HB, Saenz-Agudelo P, Planes S, Jones GP, Berumen ML (2013) Relative accuracy of three common methods of parentage analysis in natural populations. Mol Ecol 22:1158-1170

Hastings A, Botsford LW (2006) Persistence of spatial populations depends on returning home. Proc Natl Acad Sci USA 103:6067-6072

Hauser L, Baird M, Hilborn R, Seeb LW, Seeb JE (2011) An empirical comparison of SNPs and microsatellites for parentage and kinship assignment in a wild sockeye salmon (Oncorhynchus nerka) population. Mol Ecol Resour 11:150-161

Hedgecock D, Pudovkin AI (2011) Sweepstakes reproductive success in highly fecund marine fish and shellfish: a review and commentary. Bull Mar Sci 87:971-1002

Hemmer-Hansen J, Nielsen EE, Therkildsen NO, Taylor MI 
and others (2013) A genomic island linked to ecotype divergence in Atlantic cod. Mol Ecol 22:2653-2667

> Herbinger CM, Doyle R, Taggart CT, Lochmann SE, Brooker AL, Wright JM, Cook D (1997) Family relationships and effective population size in a natural cohort of Atlantic cod (Gadus morhua) larvae. Can J Fish Aquat Sci 54: $11-18$

> Horne JB, van Herwerden L, Abellana S, McIlwain JL (2013) Observations of migrant exchange and mixing in a coral reef fish metapopulation link scales of marine population connectivity. J Hered 104:532-546

- Huber W, Carey VJ, Gentleman R, Anders S and others (2015) Orchestrating high-throughput genomic analysis with Bioconductor. Nat Methods 12:115-121

> Hutchinson WF, Carvalho GR, Rogers SI (2001) Marked genetic structuring in localised spawning populations of cod Gadus morhua in the North Sea and adjoining waters, as revealed by microsatellites. Mar Ecol Prog Ser 223:251-260

> Iacchei M, Ben-Horin T, Selkoe KA, Bird CE, GarciaRodriguez FJ, Toonen RJ (2013) Combined analyses of kinship and FST suggest potential drivers of chaotic genetic patchiness in high gene-flow populations. Mol Ecol 22:3476-3494

> Johnson DW, Christie MR, Moye J, Hixon MA (2011) Genetic correlations between adults and larvae in a marine fish: potential effects of fishery selection on population replenishment. Evol Appl 4:621-633

> Jombart T, Ahmed I (2011) adegenet 1.3-1: new tools for the analysis of genome-wide SNP data. Bioinformatics 27: 3070-3071

> Jombart T, Devillard S, Balloux F (2010) Discriminant analysis of principal components: a new method for the analysis of genetically structured populations. BMC Genet 11:94

Jorde PE, Knutsen H, Espeland SH, Stenseth NC (2007) Spatial scale of genetic structuring in coastal cod Gadus morhua and geographic extent of local populations. Mar Ecol Prog Ser 343:229-237

Kardos M, Luikart G, Allendorf FW (2015) Measuring individual inbreeding in the age of genomics: marker-based measures are better than pedigrees. Heredity 115:63-72

Keenan K, McGinnity P, Cross TF, Crozier WW, Prodohl PA (2013) diveRsity: an R package for the estimation and exploration of population genetics parameters and their associated errors. Methods Ecol Evol 4:782-788

> Knutsen H, Andre C, Jorde PE, Skogen MD, Thuroczy E, Stenseth NC (2004) Transport of North Sea cod larvae into the Skagerrak coastal populations. Proc R Soc B 271: 1337-1344

Knutsen H, Olsen EM, Jorde PE, Espeland SH, Andre C, Stenseth NC (2011) Are low but statistically significant levels of genetic differentiation in marine fishes 'biologically meaningful'? A case study of coastal Atlantic cod. Mol Ecol 20:768-783

Kokko H, López-Sepulcre A (2006) From individual dispersal to species ranges: perspectives for a changing world. Science 313:789-791

> Lowe WH, Allendorf FW (2010) What can genetics tell us about population connectivity? Mol Ecol 19:3038-3051

- Marshall DJ, Monro K, Bode M, Keough MJ, Swearer S (2010) Phenotype-environment mismatches reduce connectivity in the sea. Ecol Lett 13:128-140

> Myksvoll MS, Sundby S, Adlandsvik B, Vikebo FB (2011) Retention of coastal cod eggs in a fjord caused by interactions between egg buoyancy and circulation pattern.
Mar Coast Fish 3:279-294

Nielsen EE, Gronkjaer P, Meldrup D, Paulsen H (2005) Retention of juveniles within a hybrid zone between North Sea and Baltic Sea Atlantic cod (Gadus morhua). Can J Fish Aquat Sci 62:2219-2225

Nosil P, Funk DJ, Ortiz-Barrientos D (2009) Divergent selection and heterogeneous genomic divergence. Mol Ecol 18:375-402

O'Reilly PT, Kozfkay CC (2014) Use of microsatellite data and pedigree information in the genetic management of two long-term salmon conservation programs. Rev Fish Biol Fish 24:819-848

Oliehoek PA, Windig JJ, van Arendonk JAM, Bijma P (2006) Estimating relatedness between individuals in general populations with a focus on their use in conservation programs. Genetics 173:483-496

Palsbøll PJ, Berube M, Allendorf FW (2007) Identification of management units using population genetic data. Trends Ecol Evol 22:11-16

Pampoulie C, Skirnisdottir S, Star B, Jentoft S and others (2015) Rhodopsin gene polymorphism associated with divergent light environments in Atlantic cod. Behav Genet 45:236-244

Pannell JR, Charlesworth B (2000) Effects of metapopulation processes on measures of genetic diversity. Philos Trans R Soc Lond B Biol Sci 355:1851-1864

Peakall R, Smouse PE (2006) GENALEX 6: genetic analysis in Excel. Population genetic software for teaching and research. Mol Ecol Notes 6:288-295

Pepin P, Helbig JA (1997) Distribution and drift of Atlantic cod (Gadus morhua) eggs and larvae on the northeast Newfoundland Shelf. Can J Fish Aquat Sci 54:670-685

> Pew J, Muir PH, Wang JL, Frasier TR (2015) related: an R package for analysing pairwise relatedness from codominant molecular markers. Mol Ecol Resour 15:557-561

> Pineda J, Hare JA, Sponaugle S (2007) Larval transport and dispersal in the coastal ocean and consequences for population connectivity. Oceanography (Wash DC) 20:22-39

Planes S, Lecaillon G, Lenfant P, Meekan M (2002) Genetic and demographic variation in new recruits of Naso unicornis. J Fish Biol 61:1033-1049

Pollard KS, Dudoit S, van der Laan MJ (2005) Multiple testing procedures: $\mathrm{R}$ multtest package and applications to genomics. In: Gentleman RCCV, Carey V, Huber W, Irizarry $\mathrm{R}$, Dudoit S (eds) Bioinformatics and computational biology solutions using $\mathrm{R}$ and Bioconductor, Chapter 15. Springer, New York, NY, p 249-271

> Poulsen NA, Nielsen EE, Schierup $M H$, Loeschcke V, Gronkjaer P (2006) Long-term stability and effective population size in North Sea and Baltic Sea cod (Gadus morhua). Mol Ecol 15:321-331

> Robichaud D, Rose GA (2004) Migratory behaviour and range in Atlantic cod: inference from a century of tagging. Fish Fish 5:185-214

> Rousset F (2008) GENEPOP'007: a complete re-implementation of the GENEPOP software for Windows and Linux. Mol Ecol Resour 8:103-106

Ruzzante DE, Taggart CT, Cook D (1996) Spatial and temporal variation in the genetic composition of a larval cod (Gadus morhua) aggregation: cohort contribution and genetic stability. Can J Fish Aquat Sci 53:2695-2705

> Ruzzante DE, Taggart CT, Cook D (1999) A review of the evidence for genetic structure of cod (Gadus morhua) populations in the NW Atlantic and population affinities of larval cod off Newfoundland and the Gulf of St. 
Lawrence. Fish Res 43:79-97

Ruzzante DE, Taggart CT, Doyle RW, Cook D (2001) Stability in the historical pattern of genetic structure of Newfoundland cod (Gadus morhua) despite the catastrophic decline in population size from 1964 to 1994 . Conserv Genet 2:257-269

Slatkin M (1987) Gene flow and the geographic structure of natural populations. Science 236:787-792

Stenseth NC, Jorde PE, Chan KS, Hansen E and others (2006) Ecological and genetic impact of Atlantic cod larval drift in the Skagerrak. Proc R Soc B 273:1085-1092

Svedäng H, Righton D, Jonsson P (2007) Migratory behaviour of Atlantic cod Gadus morhua: natal homing is the prime stock-separating mechanism. Mar Ecol Prog Ser 345:1-12

Taylor HR (2015) The use and abuse of genetic markerbased estimates of relatedness and inbreeding. Ecol Evol 5:3140-3150

R Development Core Team (2014) R: a language and environment for statistical computing. R Foundation for Statistical Computing, Vienna

Editorial responsibility: Philippe Borsa, Montpellier, France
Templeman W (1974) Migrations and intermingling of Atlantic cod (Gadus morhua) stocks of Newfoundland area. J Fish Res Board Can 31:1073-1092

Therkildsen NO, Hemmer-Hansen J, Hedeholm RB, Wisz MS and others (2013) Spatiotemporal SNP analysis reveals pronounced biocomplexity at the northern range margin of Atlantic cod Gadus morhua. Evol Appl 6:690-705

Wang J (2002) An estimator for pairwise relatedness using molecular markers. Genetics 160:1203-1215

> Wang J (2007) Triadic IBD coefficients and applications to estimating pairwise relatedness. Genet Res 89:135-153

> Wang C, Schroeder KB, Rosenberg NA (2012) A maximum likelihood method to correct for allelic dropout in microsatellite data with no replicate genotypes. Genetics 192: 651-669

Waples RS (2015) Testing for Hardy-Weinberg proportions: Have we lost the plot? J Hered 106:1-19

> Waples RS, Gaggiotti O (2006) What is a population? An empirical evaluation of some genetic methods for identifying the number of gene pools and their degree of connectivity. Mol Ecol 15:1419-1439

Submitted: November 4, 2015; Accepted: June 27, 2016

Proofs received from author(s): August 18, 2016 